
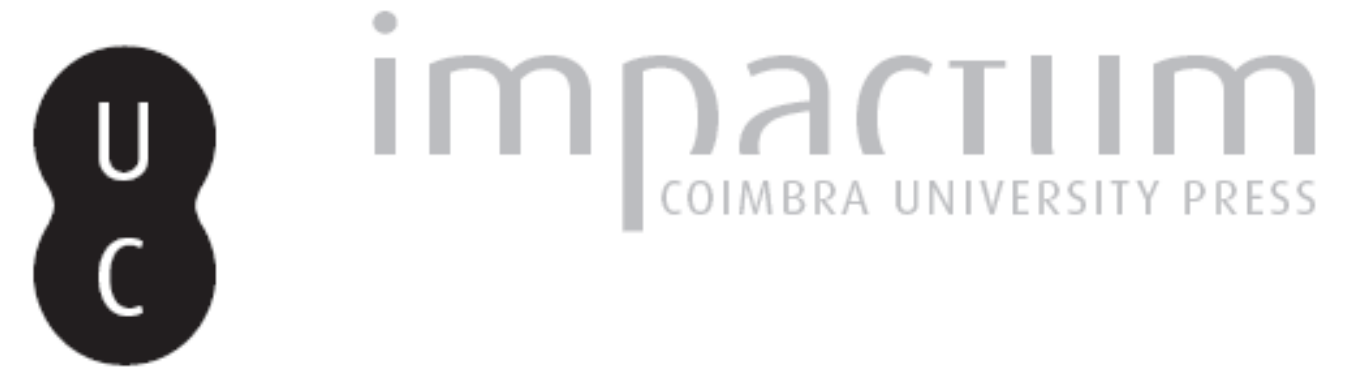

\title{
A filosofia do mito em Plotino e Proclo: um estudo comparativo
}

Autor(es): $\quad$ Cohen, Daniel; Lacrosse, Joachim

Publicado por: Annablume Clássica

URL persistente:

URI:http://hdl.handle.net/10316.2/24479

DOI:

DOI:http://dx.doi.org/10.14195/1984-249X_5_7

Accessed : $\quad$ 26-Apr-2023 14:48:59

A navegação consulta e descarregamento dos títulos inseridos nas Bibliotecas Digitais UC Digitalis, UC Pombalina e UC Impactum, pressupõem a aceitação plena e sem reservas dos Termos e Condições de Uso destas Bibliotecas Digitais, disponíveis em https://digitalis.uc.pt/pt-pt/termos.

Conforme exposto nos referidos Termos e Condições de Uso, o descarregamento de títulos de acesso restrito requer uma licença válida de autorização devendo o utilizador aceder ao(s) documento(s) a partir de um endereço de IP da instituição detentora da supramencionada licença.

Ao utilizador é apenas permitido o descarregamento para uso pessoal, pelo que o emprego do(s) título(s) descarregado(s) para outro fim, designadamente comercial, carece de autorização do respetivo autor ou editor da obra.

Na medida em que todas as obras da UC Digitalis se encontram protegidas pelo Código do Direito de Autor e Direitos Conexos e demais legislação aplicável, toda a cópia, parcial ou total, deste documento, nos casos em que é legalmente admitida, deverá conter ou fazer-se acompanhar por este aviso.

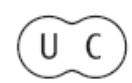



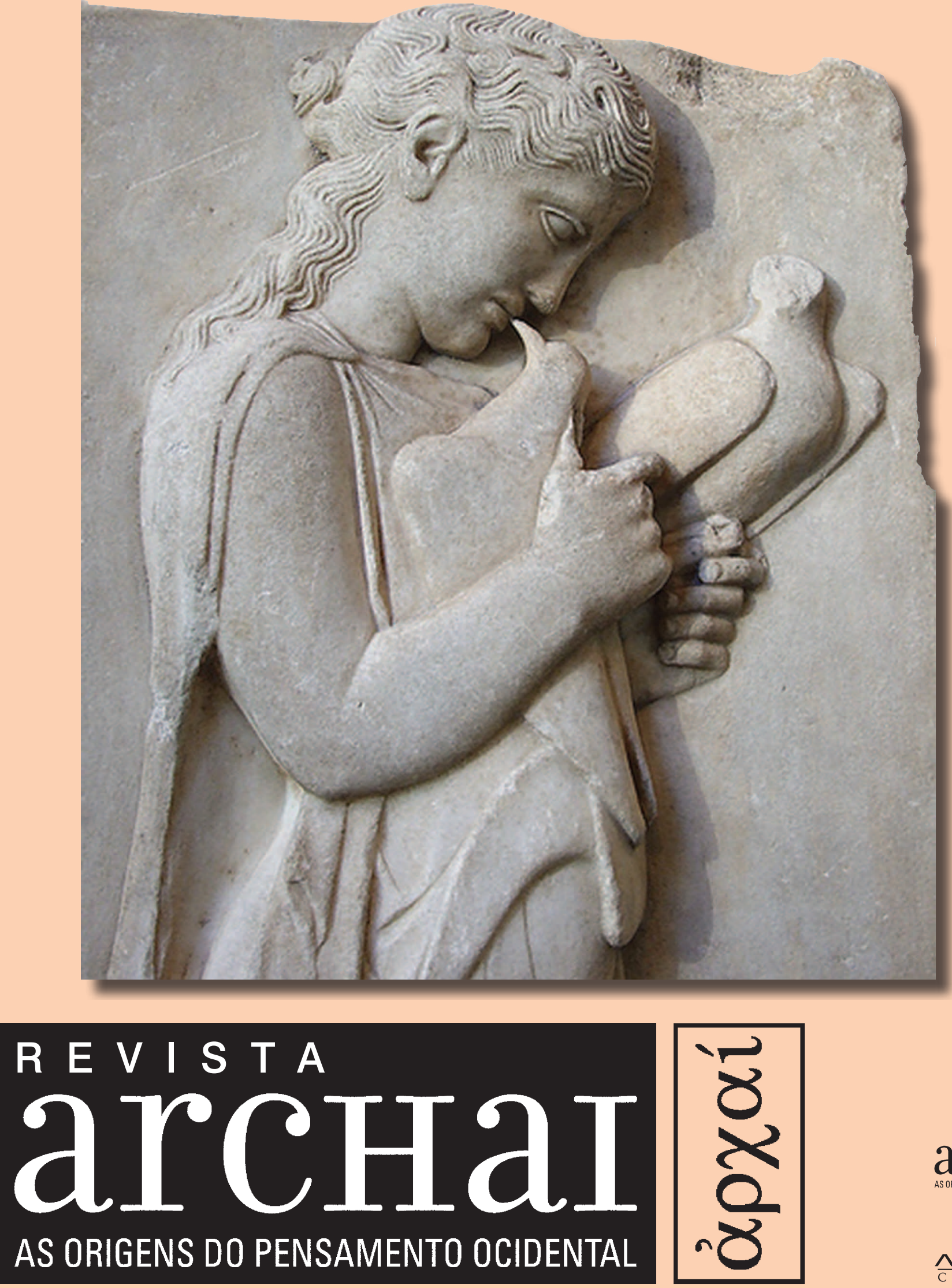


\section{A FILOSOFIA DO MITO EM PLOTINO E PROCLO. UM ESTUDO COMPARATIV ${ }^{1}$}

RESUMO: Esta contribuição resume as principais conclusões de um trabalho de comparação filosófica entre o Neoplatonismo de Plotino e Proclo, baseado na análise de suas respectivas recepções do uso metafísico tradicional de mitos antigos. Este artigo consiste no exame de duas importantes "definições 》 de mito coletadas nas Enéadas de Plotino e no Comentário à República de Proclo. Baseando-nos nestas análises, podemos dizer que tanto para Plotino quanto para Proclo o mito aparece como sendo um caso particular de logos, e podemos até mesmo afirmar que o próprio lógos é um caso particular de mûthos.

PALAVRAS CHAVE: mito, logos, Plotino, Proclo, dialética.

ABSTRACT: This contribution resumes the main conclusions of a common work of philosophical comparatism between the Neoplatonism of Plotinus and Proclus, which is based on the examination of their respective reception of the traditional metaphysical use of anciant myths. This article consists in the examination of two important "definitions" of myth collected in the Enneads of Plotinus and Proclus' Commentary on the Republic. On the basis of these analyses, it is possible to assert that, for Plotinus as for Proclus, the muthos appears as being a simple particular case of logos, and even that the logos itself is only a particular case of muthos.

KEY-WORDS: myth, logos, Plotinus, Proclus, dialectics.
1. Tradução Alaya Dullius

de Souza

2. Daniel Cohen (FNRS, Université Libre de Bruxelles); Joachim Lacrosse (Facultés Universitaires Saint-Louis, Bruxelles)

3. Ver J. Lacrosse, « Mythe et philosophie chez Plotin », em Mélanges Couloubaritsis, Paris-Bruxelas, 2008, pp. 493-501. Ver também L. Couloubaritsis, Aux origines de la philosophie européenne, Bruxelas, 1992,

p. 37-39, e « Mythe et religion : une alliance de raison », Kernos, 1, 1988, p. 111-120.

4. Optamos por respeitar as traduções dos textos gregos escolhidas pelos autores, indicando entre parênteses quais são e se foram modificadas, tal como eles o fazem no original. 0 mesmo vale para os critérios de transliteração do grego: respeitamos o modo como os autores transliteraram. [Nota da Editora]
Daniel Cohen e Joachim Lacrosse

\section{0 que é "Mito"?}

\section{1. PLOTINO}

$E_{m}$ seu tratado Sobre o Amor (III, 5 [50] 9, 24-29), Plotino apresenta uma definição paradigmática $^{3}$ do uso filosófico Neoplatônico do mito como discurso metafísico:

Mitos, se o são de fato, devem separar em tempos diferentes (merízein khrónois) as coisas sobre as quais falam, e dividir (diaireîn) de cada uma os muitos outros seres que estão juntos (homoû), mas que são distintos em posição hierárica e em poder (táxei dè ê dunámesi), em pontos em que os discursos (kaì hoi lógoi) fazem a geração das coisas não-geradas (genéseis tôn agennétonn poioûsi), e também dividem as coisas que estão juntas. Então, uma vez que tenham nos ensinado tudo que é possível ensinar, permitem que aqueles que os entenderam com seus intelectos (tôi noésanti) coloquem novamente juntos (sunaireîn) aquilo que separaram" (trad. Armstrong, modificada) ${ }^{4}$.

Há muitos pontos que precisam ser enfatizados nesta definição crucial, que permanecerão constantemente no Neoplatonismo pós-Plotino: 
1) Plotino fala sobre os "verdadeiros" mitos, e não sobre qualquer tipo de mito. Estes mitos "verdadeiros" contam histórias sobre coisas não geradas, como se tivessem sido geradas. E falam sobre realidades unas como se fossem divididas.

2) Ele caracteriza o mito como um discurso racional (lógos), dizendo que a mesma metodologia é usada por qualquer lógos que se refira aos seres inteligíveis, isto é: expressa a sincronicidade por meio da diacronicidade, e a unidade por meio da divisão.

3) Uma vez que um mito é contado através de um processo discursivo, devemos entender e captar seus ensinamentos, e este úlimo passo noético é chamado sunairesis.

Assim, qualquer análise comparativa deve enfatizar as diferenças bem como as semelhanças, mesmo quando lidamos com dois filósofos neoplatônicos. E de fato, apesar desses três aspectos metodológicos serem comuns a Plotino e Proclo, a abordagem filosófica e o significado que se dá à pratica de interpretar mitos é diferente. Dessa forma, estabeleceremos estas principais diferenças entre a abordagem pedagógica e exotérica de Plotino e a abordagem simbólica e interpretação esotérica de Proclo, e então retornar aos pontos metodológicos em comum.

Tradicionalmente, o mito é definido como um discurso falso e mentiroso que representa a verdade: Mûthos estì lógos pseudès eikonízon alétheian. Esta caracterização é encontrada, dentre outros, nas definições de mûthos dadas por Hesíodo, Platão e Plutarco ${ }^{5}$.

Plotino traz essa definição tradicional de mito para um nível metafísico ${ }^{6}$. A "mentira" do mito é agora deifinida por 1) a genealogia aplicada a coisas não geradas e 2) a divisão aplicada a coisas unidas. Mitos são usados pelo filósofo para 1) separar (merízein) o processo metafísico em tempos diferentes, e 2) dividir (diaírein) os seres inteligíveis que estão juntos, mas diferem em relação a sua posição hierárquica (táxis) e seu poder metafísico (dúnamis).

Agora, se observarmos a prática de Plotino de contar histórias míticas "verdadeiras" nas Enéadas, é sempre uma referência ao "back-ground" metafísico de sua filosofia: a relação entre Alma, Intelecto e o Um, e, de modo mais geral, uma referência às relações causais e hierárquicas entre muitas hupostaseis eternas ou seres inteligíveis. Diferente de Porfírio ou Proclo, Plotino não tem nenhuma consideração pelo significado literal das histórias míticas, considera apenas seu aspecto metafísico.

Para este propósito, que envolve clarificação do pensamento (delôsis) e pedagogia (didaskalía), Plotino usa o termo mûthos para falar sobre Narciso (I, 6 [1] 8, 11), Poros e Penia (III, 5 [50] 9, 24 ; III, 6 [26] 14, 10), Prometeu (IV, 3 [27] 14, 5), Cronos $(V, 1[10] 7,32)$, Linceu $(V, 8$ [31] 4, 26) e Eros e Psique (VI, $9[9] 9,26)^{7}$, enquanto também se refere a muitos outros mitos sem usar o termo mûthos ${ }^{8}$.

Tomemos um exemplo famoso, Plotino interpreta a Teogonia de Hesíodo (126-210; 453506; 617-735) da seguinte forma: Urano é o Um. Seu filho, Cronos, é o Intelecto, que devora sua amada prole (as Idéias) para evitar que elas cresçam com sua mãe Réia (a Matéria). Zeus, o último filho nascido de Cronos, é a Alma, que coloca seu pai em correntes e sai, a fim de expressar no mundo sensível a beleza de seu avô, pai e irmãos ( $\mathrm{V}, 8$ [31] 10-13; V, 1 [10] 7; III, 8 [30] 11, 33-45; V, 5 [32] 3, 20-23).

Cada geração, do Um ao Intelecto, do Intelecto à Alma, não é temporal: estas coisas, diz Plotino (Cf. II, 9, 3, 11-14), "sempre" foram engendradas, e sempre serão. Como veremos, Plotino, para explicar seus próprios ensinamemtos filosóficos, está seguindo os mesmos princípios metodológicos para dar uma definição de mûthos como um discurso falso e mentiroso que representa a verdade. 0 mito aparece como um caso particular de discurso, como um modo concreto de explanação filosófica. Isto levou Jean Pépin, exagerando um pouco, a falar da prática de Plotino de uso do mito como uma "técnica agnóstica, flutuante e utilitária" ${ }^{9}$.

É importante notar que, de um lado, Plotino geralmente considera as histórias contadas pelo "divino" Platão, e, por outro lado, os mitos tradicionais daqueles que ele chama de "poiêtai" (I, 1 [53] 12, 31 ;V, 5 [32] 8, 6 ; VI, 7 [38] 30, 29), Homero e Hesíodo, colocados no mesmo
5. Hesiod, Theog. 27-28; Plato, Rep. 377a ; Crat. 408c ; Plutarch, De glor. Ath., 4, 348b.

6. Plotino está seguindo a tradição iniciada pelo Neopitagorismo e por Plutarco contra a exegese alegórica dos Estóicos e dos Epicuristas. Sobre estas abordagens contrastantes, ver J. Pépin, Mythe et allégorie, Paris, 1976, 2nd edição.

7. J. H. Sleeman e G. Pollet, Lexicon Plotinianum, LeuvenLeiden, 1980, s.v. « mûthos 》.

8. Ver J. Pépin, « Plotin et les mythes », Revue philosophique de Louvain, 53, 1955, pp.5-27 e L. Brisson, Introduction à la philosophie du mythe. 1. Sauver les mythes, Paris, 1996, pp.104-114

9. J. Pépin, «Plotin et les mythes », Revue philosophique de Louvain, 53, 1955, p.14. 
nível. Ele está ciente da existência em comum de interpretações mistéricas de mitos tradicionais ( $c f$. V, 1 [10] 7, 32), mas parece não atribuir um papel importante a isto.

\section{2. PROCLO}

Proclo é um filósofo muito mais sistemático que Plotino. Isto pode ser dito também sobre sua teoria a respeito dos mitos, que lida com o complexo "background" da metafísica de Proclo e a sucessiva ordem de sua hierarquia divina, incluindo Hênadas, Deuses inteligíveis, Deuses inteligível-intelectivos, Deuses intelectivos, Deuses hipercósmicos e encósmicos, e a multiplicidade de Anjos e Demônios. Com tal pano de fundo metafísico, a concepção procleana do discurso mítico é, portanto, obviamente mais circunstancial e sofisticada do que a plotiniana, e a esta concepção muitas distinções e explici-tações são adicionadas.

No sexto ensaio de seu Comentário sobre a República (In Remp. I, p. 77.13-28 Kroll), Proclo fornece um relato geral sobre mito e alguns de seus aspectos metodológicos, que seguem o mesmo padrão da definição plotiniana de mito. Ele explica que os "pais da mitologia" (hoi tês muthopoías patéres), os quais ele chama de theologoi, produziram seus mitos da mesma forma que a Natureza produz o mundo sensível: ambos, ele diz, representam a realidade indivisível como dividida, representam 0 que é eterno por meio de uma progressão temporal, o inteligível pelo sensível, o imaterial como sendo material, aquilo que não tem extensão, como se o tivesse, e o que é estável, como mutável.

Desta forma, nos diz Proclo, o mito pode se referir aos Deuses transcendentes ao usar, de modo a descrevê-los, alguns termos que são opostos e alheios a eles. Ao fazer isso, os mitos revelam-se a si mesmos claramente como falsos, como discurso mentiroso, e convidam a descobrir a verdade teológica por trás do conteúdo literal.

É um fato bem conhecido que Platão baniu os poetas de sua República devido aos conteúdos explícitos, cheios de transgressões imorais, das produções míticas: castração, adultério, assassinatos e assim por diante. Para Proclo, este conteúdo imoral é a característica saliente do discurso mítico, precisamente por ser o mais oposto ao que os Deuses de fato são.

Se alguém se interessa pelo sentido literal dos mitos, apenas aqueles genuinamente Platônicos, como aqueles do Timeu e do Político, são próprios para a educação. Mas ao tratar dos mitos tradicionais de Homero e Hesíodo, as coisas são diferentes. 0 verdadeiro significado de tais mitos, diz-nos Proclo, consiste de uma "doutrina secreta", e apenas filósofos "capacitados" podem atingir um completo entendimento destes. (Plat. Theol. V, 3, p. 18.2 sq. Saffrey-Westerink).

Em seu Comentário sobre a República, Proclo também distingue níveis diferentes na poesia de Homero. Para ele, a condenação feita por Platão sobre a poesia mítica refere-se apenas ao que ele chama do nível mais baixo desta poesia, onde Homero não dá nenhum ensinamento teológico. Mas é claro, para ele, que Platão nunca formulou este banimento em relação aos ensinamentos teológicos mais elevados fornecidos pela mitologia tradicional. Platão rejeitou apenas o uso educativo desta poesia, e o irracional, imoral e blasfêmo significado superficial desta forma aparente.

Para Proclo, aquela forma aparente e os elementos da estrutura narrativa dos mitos tradicionais são símbolos (súmbola ou súnthemata) da estrutura da realidade inteligível. Este ponto é talvez o mais importante e original da leitura metafísica de Proclo da mitologia tradicional: símbolos, ele diz "não são imitações daquilo que simbolizam" (tà gàr súmbola, toúton hôn esti súmbola, mimémata ouk éstin : In Remp. I, p. 198.15-16 Kroll), mas, ao contrário, podem ser o exato oposto da natureza das realidades que simbolizam. (In Remp. I, p. 77.22).

É importante notar que a palavra súmbolon, que para Proclo possui um significado mistérico e religioso especial, não aparece nas Enéadas de Plotino, a não ser pela ocorrência do termo súmbolikos, em referência aos Pitagóricos (V, 5 [32] 6, 27). Para Proclo, o símbolo claramente caracteriza a natureza do discurso mítico tradicional e suas referências teológicas aos níveis mais altos da realidade. 
Em sua Teologia Platônica (I, 4), Proclo dá um importante novo relato epistemológico sobre o mito, que lida com outra principal característica da forma mítica de discurso:

Este modo de mitologia (ho tês muthologías trópos) é antigo, que revela os [princípios] divinos por meio de dicas ocultas (di' huponoiôn), espalha muitos véus (parapetásmata) sobre a verdade, e imita a natureza, que demonstra formas sensiveis, materiais e divisiveis ao invés de seres inteligiveis, imateriais e indivisíveis, e que, dos seres verdadeiros, cria imagens e mentiras (tôn alethinôn eídola kaì pseudôs ónta kataskeuázei). (Plat. Theol. I, 4, p. 21.7-12).

Aqui vemos a maior discordância entre a atitude de Plotino e a de Proclo em relação aos mitos. Enquanto em Plotino o mito parece ser apenas um instrumento metafórico para elucidação filosófica e com um propósito pedagógico, Proclo define o discurso mítico como uma expressão simbólica, enigmática, obscura e velada de verdades teológicas superiores. Proclo também relaciona claramente 0 mito aos mistérios e ritos teúrgicos, uma dimensão religiosa a qual Plotino não parece conceder uma função importante.

Mas podemos afirmar que, apesar desta grande diferença, o mito significa, tanto para Plotino quanto para Proclo, um discurso declarado por sábios homens da Antiguidade, que lida com a realidade inteligível e usa alguns princípios metodológicos que, por fim, como veremos, regem todo o tipo de discurso racional que se refere a estruturas unas, eternas e inteligíveis.

\section{Mûthos como um caso específico de lógos}

\section{1. PLOTINO}

\section{1. 1. Mûthos como logos filosófico}

Voltemos à nossa definição Plotiniana de mito (III, 5 [50] 9). Alguns tradutores das Enéadas introduziram uma distinção entre mûthos e lógos na segunda parte da definição, e isto não está no texto grego. Bréhier entende aqueles lógoi como «raciocínios de Platão», Armstrong os torna «discussões racionais», enquanto Pierre Hadot traduz: «discursos racionais».

Em nossa opinião quando Plotino afirma que os lógoi criam gerações de seres não-gerrados e separações entre as coisas que estão unidas, ele apenas quer dizer que o mito é uma aplicação particular de alguns princípios metodológicos que pertencem ao lógos, entendido por « discurso », « fala », « história » ou « razão ».

Como um discurso que fala sobre coisas eternas como se tivessem nascido, e sobre coisas unificadas como se tivessem sido divididas, o mito traz à luz uma distorção que pertence a todo discurso filosófico deste tipo. Os discursos, incluindo o discurso mítico, necessitam usar uma anterioridade e posterioridade para transmitir a estrutura metafísica do mundo inteligível. 0 mito, longe de ser diferente do lógos, é na verdade um caso particular, até mesmo paradigmático, do lógos.

Por exemplo, a definição Plotiniana de mûthos sustenta os mesmos princípios metodológicos daqueles afirmados em sua exegese do mito de Timeu, que, como Platão, ele chama de $\operatorname{lógos}^{10}$. Quando Platão diz que o demiurgo "era bom" (Tim. 29c), diz Plotino, ele utiliza o pretérito imperfeito para "explicar" as coisas, mas isso não significa que estas coisas aconteceram em algum momento no tempo (III, 7 [45] 6, 50-57). E quando Platão fala sobre o "nascimento" do mundo, que sempre foi e sempre será (Tim., 38c), ele está se referindo à conformidade do mundo sensível ao Intelecto, que o faz "sempre" subsistente (III, 2 [47] 1, 22-26 ; II, 2 [14] 1, 1 sq. ; II, 9 [33] 7, 1-2).

Também é para esclarecer nosso pensamento que usamos o modo de pensar chamado epinoia, que permite que o lógos e a dianoia criem a separação dualista como "corpo e alma", ou "material e forma", quando a verdade é que nunca houve nem nunca haverá um corpo sem alma e uma matéria sem forma (IV, 3 [27] 9, 14-20).

De modo mais geral, pelo simples fato de usarmos um lógos, diz Plotino, temos que atribuir uma génesis para as coisas que são "sempre" (aei) a fim de dar a elas uma causa (aítia) e uma posição hierárquica (táxis) (V,1 [10] 19-22).
10. Devemos lembrar que a palavra mais usada por autores gregos, especialmente Platão, para se referir ao que chamaríamos de mito é nada menos que a palavra lógos. 
Plotino agora está descrevendo a filosofia geral das Enéadas de forma quase idêntica ao modo que ele descreve os mitos na definição que citamos. Talvez alguém possa até mesmo ler todo o conjunto das Enéadas como um grande "Mito", seguindo estes mesmos princípios metodológicos.

\section{1. 2. A alma racional como um merizôn noûs}

Há muitas afirmações Neoplatônicas sobre a prática discursiva como um processo humano e artificial de divisão. Tais afirmações podem ser igualmente feitas sobre os mitos. Como Plotino, Proclo e Damáscio estão perfeitamente cientes que, quando nos referimos aos seres inteligíveis, as divisões são feitas por nós: Hèmeis de hoi merizontes (Damáscio, In Parm., IV, 963, 21-22 Cousin ; De Princ., I, p.4, 6 Combès-Westerink).

Como um meio termo entre a sensação e o intelecção, tempo e eternidade, e assim por diante, a função racional da alma é descrita por Plotino como um merizôn noûs, um "intelecto que divide" (V, 9 [5] 8, 20-22) que em parte é diferente e em parte

11. Ver J. Lacreosse, La philosophie de Plotin. Intellect et discursivité, Paris, 2003.

12. Ver J. Lacrosse, L'amour chez Plotin, Bruxelas, 1994. é similar ao Intelecto universal ${ }^{11}$.

Quando a alma cria uma divisão dentro dos inteligíveis, ele diz, a distinção ja está, e eternamente é, feita pelo Intelecto. A divisão feita pela alma é apenas uma imagem da eterna distinção feita pelo Intelecto. E, ele interessantemente acrescenta, a intelecção da anterioridade e posterioridade entre as coisas inteligiveis não é temporal, mas se refere à suas posições hierárquicas (táxis) (IV,4 [28] 1,25-29).

\section{1. 3. Mito e Processo Dialético}

Por fim, e igualmente importante, o uso filosófico do mito pode ser relacionado ao processo dialético (I, 3 [20] 4 e I, 3 [20] 5, 1-4), que expressa aquilo que é inteligível por meio de divisões do Intelecto em gênero, espécie e singularidades ( $c f$. VI, 2).

É óbvio que a definição de Pltoino de discurso dialético envolve os mesmos passos metodológicos que sua definição de mito: divisão de coisas unas, e discurso temporal aplicado àquilo que é eterno, de modo a expressar as relações causais e hierárquicas entre eles.

Além do mais, como na dialética, o entendimento de um mito envolve um sunairèsis que corrige a distorção introduzida pela diairèsis e consiste em captar juntos com o Intelecto o que foi dividido pelo lógos.

0 final do tratado Sobre o Amor (III, 5 [50] 9, 29sq.), que segue a definição Plotiniana de mito, é um ótimo exemplo de sunairèsis mítico-dialética, aplicada ao mito Platônico de nascimento de Eros, filho de Poros e Penia ${ }^{12}$.

\section{1. 4. Mito e Lógos universal}

Na verdade, o que pode ser dito sobre mitos e lógoi como "discursos" também é verdadeiro para o lógos como um processo universal de manifestação do inteligível para dentro da Alma do Mundo. Por exemplo, o lógoi spermatikoi são as expressõs desdobradas e extensivas das Ideias, que estão no Intelecto de uma forma concentrada e intensa.

De modo geral, o lógos, diz Plotino, não é um, mas dividido (memerisménon), pois utiliza a natureza corpórea com propósito de pesquisa, e aplica os mesmos princípios aos seres inteligíveis (VI, 5 [23] 2, 2-5). Novamente, esta definição geral de lógos é bastante próxima às afirmações Plotinianas sobre mito e discursos genealógicos.

\section{2. PROCLO}

\section{2. 1. Mûthos como lógos filosófico}

Assim como para Plotino, podemos dizer que a definição de Proclo da forma mítica do discurso teológico é bastante próxima ao modo dele falar sobre o lógos em geral, e da dialética como um processo de dividir o que está unificado e juntar o que foi separado.

De fato, o relato de Proclo sobre o mito (In Remp. I, 77, 13-28) é bastante próximo a sua concepção geral de lógos como um processo discursivo. Vimos que, de acordo com Proclo, o mito expressa realidades não-divididas, eternas, 
inteligíveis, imateriais, sem extensão e estáveis por meio de elementos de narração divididos, temporais, sensíveis, materiais, progressivos e vastos. Isto certamente também podemos afirmar a respeito do lógos.

\section{2. 2. A alma racional como um merizôn nous}

Como afirma Proclo, discursos (lógoi) são imagens intelectivas (noeseis), pois desvelam os inteligíveis que estão centrados juntos, e expressam e traduzem em partes o que não tem parte alguma (Plat. Theol., V, p. 65.23sq.): o logos, ele diz, deve estar de um modo desvelado (aneiligmenôs) e aquilo ao qual ele se refere está em um modo concentrado (em Tim. I, p. 341.6-11 Diehl).

Mas porque devem os discursos ser dessa forma? Por que são produtos de almas humanas. A expressão discursiva, diz Proclo, é a principal característica da alma individual racional: logos dè psukhaîs prosèkei kai tè taxei tôn psukhôn (In Tim. III, p. 243.25). E já que a natureza e a atividade destas almas racionais são ontologicamente intermediadas entre tempo e eternidade (El. Th., prop. 191), entre princípios inteligíveis indivisíveis e sua manifestação dividida no mundo material ( $E l$. Th. Prop. 190), isto implica, para Proclo, que eles não são capazes de captar ao mesmo tempo toda a natureza unificada das realidades inteligíveis. (In Remp. II, p. 288.15sq.).

Portanto, o lógos deve introduzir divisão, descontinuidade e fragmentação temporal, de modo a traduzir realidades eternas e unificadas ao nível das almas humanas (In Tim. III, p. 243.8-13). Longe de acreditar que as divisões discursivas do logos são aplicáveis a tais seres inteligíveis, tanto Plotino quanto Proclo claramente afirmam que estas divisões e separações temporais são nossa forma de expressar as realidades inteligíveis, e que devemos captar e unir intelectualmente o que foi separado pelo discurso, de modo a alcançar sua referência ontológica.

\section{3. 3. Mito e Processo Dialético}

Podemos acrescentar que este processo metodológico de divisão inerente ao lógos mítico é análogo ao processo discursivo de desvelamento do mundo inteligível usado pela ciência dialética (In Parm. I, 653.21-28 ; In Eucl. 44.15 Friedlein).

Esta analogia estrutural consiste na descrição que Proclo dá tanto da maneira dialética quanto mítica de discursar: os mitos, ele diz, expressam as estruturas do mundo inteligível ao imitar a processão dos seres e sua manifestação em uma forma visível e figurativa. (In Remp. I, p. 77.13sq.), enquanto que os discursos dialéticos o fazem imitando a processão da realidade vinda do Um, e o retorno desta a este. (Plat. Theol. I, 9, p. 40.7-8).

A analogía entre mûthos e lógos dialético é clara, apesar de haver uma diferença maior no fato de que a dialética não usa nenhum tipo de ocultamento ou símbolos materiais não acurados, mas apenas conceitos filosóficos claros (noémata). Contudo, Proclo, de acordo com o testemunho de Damáscio, foi capaz de falar sobre a obra mais dialética de Platão, o Parmênides, como a teogonia do próprio Platão ${ }^{13}$.

\section{4. 4. Mito e Lógos universal}

Nesta visão, o mito aparenta ser um caso particular de lógos discursivo, e, por sua vez, o lógos discursivo parece ser um caso particular do processo universal do lógos cósmico, que constitui a operação fragmentada caracterizando o processo cosmológico da atividade intelectual demiúrgica.

Em uma notável passagem de sua Teologia Platônica (I, 29, p. 124.12sq.), Proclo estabelece uma precisa analogia entre o lógoi mítico dos poetas tradicionais, a atividade Intelectual demiúrgica, e o conhecimento científico discursivo.

Assim, as afirmações implicitas em Plotino sobre a relação entre mûthos e lógos como um processo universal de manifestação da realidade inteligível na Alma do Mundo são mais explícitas em Proclo.
13. Cf. Damascius, In Parm. II p. 84.14-15 Combès-Westerinck Theol. Plat. I, 7, p. 31.7-27; III, 7, pp. 28.22-29.6 SaffreyWesterinck. 